\title{
O RAP CONTRA O RACISMO: A POESIA E A POLÍTICA DOS RACIONAIS MC'S
}

\author{
RAP MUSIC AGAINST RACISM: THE POETRY AND POLITICS OF \\ RACIONAIS MC'S
}

\author{
EL RAP CONTRA EL RACISMO: LA POESÍA Y LA POLÍTICA DE LOS \\ RACIONAIS MC'S
}

\author{
Gabriel Gutierrez Mendes \\ Professor e pesquisador do departamento de \\ Comunicação das Faculdades Integradas \\ Hélio Alonso. \\ gabriel.mendes34@gmail.com
}

\section{Resumo}

O artigo parte da compreensão do Hip Hop como uma forma cultural de forte viés político, caracterizada como um fórum de debate e de resistência dos negros na diáspora, para analisar a abordagem da questão racial no rap dos Racionais MC's. Forjado num momento de aguda crise econômica, o grupo foi elaborando ao longo da carreira um discurso sobre a vida do jovem negro da periferia de São Paulo que rompeu com a mitologia da democracia racial e a miragem da harmonia nas relações entre as raças no Brasil e ofereceu ao seu público um ethos através do rap. Valendo-se do instrumental teórico dos Estudos Culturais, o trabalho investiga os diversos aspectos políticos e culturais deste discurso a partir da análise das letras de combate ao racismo e autoafirmação para os negros presentes na música pouco cordial dos Racionais MC's.

Palavras-chave: Racionais MC's. Rap. Racismo

\begin{abstract}
The article starts from the understanding of Hip Hop as a cultural form with a strong political perspective and as a discussion forum of black resistance in the diaspora, and analyses the Racionais MC's approach to rap. Forged at a time of economic crisis, the group developed a
\end{abstract}


discourse about the life of black youth in the outskirts of São Paulo. The Racionais' lyrics break with the myth of racial democracy and the mirage of harmonious relations between the races in Brazil and offer their audience a different ethos through rap. Drawing on the theoretical tools of Stuart Hall's Cultural Studies, the article investigates the political and cultural aspects of the group's work by analysing the self-affirmative and critical lyrics.

Key words: Racionais MC's. Rap. Racism.

\section{Resumen}

El texto comienza con la comprensión de Hip Hop como una forma cultural de fuerte carácter político, pensada como un foro de discusión y resistencia de los negros en la diáspora, para analizar el enfoque de raza en el rap Racionais MC's. Forjado en un momento de aguda crisis económica, el grupo creo un discurso musical acerca de la vida del joven negro de São Paulo que rompió con la mitología de la democracia racial y el espejismo de las relaciones armoniosas entre las razas en Brasil, y ofreció a su público un ethos a través del rap. Sobre la base de las herramientas teóricas de los estudios culturales, el ensayo investiga los diversos aspectos políticos y culturales de este discurso a partir del análisis de la poesía de autoafirmación para los negros presente en la música anticordial de Racionais MC's.

Palabras clave: Racionais MC's. Rap. Racismo

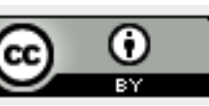

Esta obra está licenciada sob uma Licença Creative Commons

\section{INTRODUÇÃO}

Em 2014, os Racionais MC's chegaram aos 25 anos de carreira consolidados como o maior grupo de rap do Brasil. Sucesso de público e crítica, o grupo de São Paulo fez seu nome no hip hop nacional tendo como atributo marcante o contorno político das suas letras. Levando a sério o chamado "quinto elemento" da cultura hip hop, a "consciência" (os outros quatro são o grafite, o DJ, o MC e a dança Break), Mano Brown, DJ KL Jay, Edi Rock e Ice Blue construíram uma estética musical que serviu de alicerce para a produção de um discurso poético e político pouco cordial, combativo em relação ao racismo e distante das conciliações 
características da cultura política brasileira. Articulada a esse discurso de combate ao "sistema", nasceu uma poesia que afirmou a autoestima dos negros da periferia urbana contemporânea do Brasil. Assim, os Racionais foram pioneiros e criaram um rap que teve impacto sobre seu público imediato e o grande público nacional, inclusive a imprensa. Conjugaram um estilo próprio, referências à música negra americana e elementos do sambarock, da MPB e da música negra pop brasileira dos anos 70 .

O presente artigo tem como objetivo geral compreender o rap como uma manifestação da cultura negra da diáspora revestida por uma profunda dimensão política e ética. $\mathrm{O}$ propósito específico é investigar como os Racionais abordaram a questão racial na sua obra. Essa abordagem é homogênea ao longo da carreira do grupo? Quais foram os elementos do discurso sobre a vida do jovem negro da periferia brasileira elaborado por eles que tanto fascinaram os fãs dos Racionais e deu ao grupo o enorme sucesso e prestígio de que ele desfruta? Atentos às características da vida na periferia da maior cidade do país, os Racionais criaram um imaginário (Bertelli, 2012) complexo sobre o cotidiano no "gueto", e sobre formas ativas de conduzir a vida ali. Que significados de resistência e autoestima foram esses? Que interpretação da realidade foi esta que encantou tantos jovens, extrapolou os limites do rap e fez com que artistas de fora do mundo do hip hop também reconhecessem o trabalho musical e político dos Racionais? Consciente das estatísticas referentes às taxas de homicídios dos jovens negros, as letras dos Racionais versaram sobre um desafio ético: encarar o cotidiano na periferia de São Paulo com dignidade e inteligência, lidando de forma altiva com as possibilidades e encruzilhadas que a vida na cidade violenta, racista e segregada apresenta para seus habitantes ${ }^{1}$. Este trabalho analisa os diversos aspectos políticos e culturais do grupo e suas letras que abordam a temática racial, para, assim, compreender as múltiplas dimensões do discurso de combate ao racismo e de afirmação de autoestima presente na música dos Racionais.

\section{2 “UM REVÓLVER ENGATILHADO DENTRO DA MENTE"}

\footnotetext{
${ }^{1} \mathrm{O}$ contexto socioeconômico em que nasceram os Racionais é marcado por uma aguda crise social, caracterizada pelo aumento do desemprego e das desigualdades e o crescimento da violência urbana no país. Durante esse período, a região metropolitana de São Paulo intensificou sua histórica segregação espacial (SILVA, 1998). Houve aumento das distâncias sociais e acirramento das contradições do cotidiano por conta do surgimento do que Caldeira (1997) chama de "enclaves fortificados": condomínios de elite que colocam lado a lado geograficamente, mas separados por muros e seguranças armados, as classes altas e médias e os moradores das favelas. Para uma descrição aprofundada da relação entre as características sociais e espaciais da cidade de São Paulo e o rap dos Racionais MC's, ver Gutierrez (2014).
} 
A origem do movimento que enseja a existência artística dos Racionais remete aos anos de 1970. Nascido de uma conexão EUA-Jamaica ${ }^{2}$, o movimento Hip Hop emerge na periferia negra e latina do mundo ocidental no final do século XX como uma manifestação cultural ao mesmo tempo de caráter artístico e político. Seu braço musical é o rap, que neste contexto, pode ser analisado como uma espécie de vocalização de críticas e demandas relacionadas à denúncia e à resistência às opressões experimentadas pelos negros da diáspora africana. Kellner (2001, p. 230) define, o rap como uma espécie de "fórum cultural onde os negros urbanos podem expressar experiências, preocupações e visões políticas”. De certa forma, é através da música que os negros contam a sua história na diáspora. Hall (2003) chega a afirmar que a música é a real estrutura profunda da vida cultural do povo negro, uma vez que ele se encontra deslocado da cultura logocêntrica. Simultaneamente uma linguagem musical e um discurso crítico do poder, o rap é o episódio contemporâneo de uma longa tradição de subversão cultural negra, em que a contestação social e a manifestação dos anseios por liberdade são realizadas através da música e da performance (ROSE, 1994).

Neste caso, a música é observada como uma forma de resistência cultural. No campo da cultura há espaço aberto para ideias e práticas que confrontem a estrutura social, política e econômica de uma dada sociedade (DUNCOMBE, 2002). Dentro destes espaços, podem ser construídos símbolos e significados que, pelo caráter compartilhado do processo cultural, passam a ser sentidos comuns experimentados por uma comunidade específica. Essas formas culturais podem produzir um terreno coletivo de conhecimento sobre as condições sociais dos indivíduos envolvidos naquela localidade (ROSE, 1994). Assim, as interpretações compartilhadas podem desempenhar o papel de fazer nascer laços culturais que alimentem o ímpeto de resistência às opressões daquela comunidade. Esse é o caminho traçado para a reflexão sobre o rap político dos Racionais: ouvi-lo como uma arma poética - um "revólver engatilhado dentro da mente", como canta Edi Rock na música "Na fé firmão" - mobilizada dentro campo da cultura como artifício discursivo para a produção de significados associados à crítica e ao combate ao racismo e às desigualdades brasileiras, e utilizado como um vetor de afirmação de autoestima coletiva para as populações negras das favelas brasileiras.

\section{ATRÁS DA "FÓRMULA MÁGICA DA PAZ"}

\footnotetext{
${ }^{2}$ A Jamaica tem papel especial no surgimento do Hip Hop. O jamaicano Kool Herc é visto no movimento como o primeiro DJ do gênero. Imigrante nos EUA, Herc criou sua equipe de som inspirado nas sound systems de seu país de origem.
} 
Limítrofe, o Hip Hop nasceu no gueto empobrecido de Nova York como um movimento localizado na fronteira entre a arte e a política. Nas artes, como mencionado, seu aspecto musical é o rap, que utiliza os instrumentos tecnológicos de áudio dos DJs para viabilizar uma bricolagem de sons variados já existentes. Além deste material sonoro, há a forma e o conteúdo das letras dos mestres de cerimônias (MCs), que mais falam do que cantam, relatam as cenas da vida cotidiana e contam histórias de suas localidades, emulando a tradição americana da spoken poetry (poesia falada) e a tradição africana dos dozens e toasts, em que a oralidade é o elemento central na fala de rua (MACEDO, 2011). Além da música, o movimento originariamente contempla também as artes visuais, com o grafite, e a dança, com o break.

No entanto, no que se refere à sua dimensão política, o Hip Hop é mais do que um discurso crítico em relação aos problemas sociais enfrentados pelos seus criadores. Num sentido mais filosófico, ele engendra algo além das formas artísticas de expressão relacionadas à cultura de rua. Ele representa também a criação de uma consciência que amarra sua configuração política como uma subcultura periférica e juvenil. Esta consciência é atravessada por todos esses elementos artísticos e, a partir deles, organiza um sentido ético para a existência dura e repleta de adversidades concretas e subjetivas dos moradores dos guetos do mundo todo.

Através da afirmação da força para o combate simbólico por meio da arte, então, o Hip Hop cria terreno para o surgimento de uma política da vida cotidiana, que se apresente como ética de resistência e para seus adeptos. E assim abre espaço para um movimento existencial, que viabiliza a constituição de autoestima para estes sujeitos e um lugar para seus desejos. Desta maneira, a música e a cultura funcionam também como gatilhos para a "luta" numa esfera micropolítica (TAKEUTI, 2010), pois fazem nascer movimento de investimento em vidas circunscritas em entornos que são predominantemente de desinvestimento. Aqui a arte gera o que Rose (1994) chama de "narrativa de possibilidade". Desta "ética" do hip hop, portanto, emerge uma maneira de falar, vestir, andar, ser e, finalmente, agir ${ }^{3}$. Revestido por essa dimensão micropolítica, o quinto elemento do hip hop sustenta todos os outros e reforça a dimensão (macro) política do movimento.

\footnotetext{
${ }^{3}$ Neste sentido, cabe o paralelo com Hall (2003), que enfatiza o papel do estilo e do corpo como elementos de autenticidade da cultura popular negra. Segundo o autor, o estilo é visto pelos críticos apenas como embalagem, mas no repertório negro ele frequentemente é em si o material do acontecimento. No que se refere ao corpo, Hall diz que os negros o utilizam como uma verdadeira tela de representação, já que frequentemente ele é o único capital cultural de que dispõem.
} 
Esse vetor ético-político é central no rap nacional, pois ele oferece uma alternativa tanto ao crime como à subordinação pelo trabalho precarizado, característica marcante de uma realidade socioeconômica largamente hierarquizada como a brasileira. Pioneiros no país, os Racionais desenvolveram, na sua música e atitude, significados que trabalharam neste sentido, representando este tipo de saída ética, como facilmente se identifica em músicas como "Vida Loka I" e "Vida Loka II". Em busca do que chamam de uma "fórmula mágica da paz", o grupo criou um discurso poético, ético e quase profético no que se refere à oferta de uma versão alternativa a respeito das possibilidades de uma vida digna para os jovens negros das periferias do país.

\section{4 "PELAS MARGINAIS OS PRETOS AGEM COM REIS"}

Em termos culturais, o fenômeno do rap dos Racionais está relacionado a um contexto mais amplo de transformações nas possibilidades da cultura oriunda das periferias globais, em que "o pós-moderno global registra mudanças estilísticas na dominante cultural" (HALL, 2003, p.337). Apesar de advertir que os negros têm uma relação ambígua com o pósmodernismo ${ }^{4}$, Hall argumenta que, no mundo contemporâneo, é possível ver uma mudança cultural em relação ao modernismo europeu dominante no século XX: a crescente emergência rumo às práticas populares e às práticas que tratem de narrativas locais. A valorização desses aspectos da vida cultural está relacionada ao descentramento de antigas hierarquias e grandes narrativas. Neste contexto, afirma o autor, "esse descentramento ou deslocamento abre caminho para novos espaços de contestação, e causa uma importantíssima mudança na alta cultura das relações culturais populares, apresentando-se, dessa forma, como uma importante oportunidade estratégica para a intervenção no campo da cultura popular” (HALL, 2003, p. 337). No que pese a produção musical politizada dos Racionais, o Hip Hop parece ser exatamente a concretização de uma dessas oportunidades de intervenção cultural em que questões políticas relacionadas à desigualdade e ao racismo são abordadas explicitamente na música produzida pelos grupos sociais que sofrem as consequências diretas destes fenômenos.

A força renovadora destas formas culturais advindas das margens pode ser associada à luta de afirmação de uma política da diferença, que legitimou o surgimento de novas

\footnotetext{
${ }^{4}$ Shusterman (1998), ao analisar o Rap com linguagem artística, caracteriza-o como um gênero cultural essencialmente pós-moderno, por sua apropriação reciclada de músicas que já existem (com menos espaço para a criação original), pela mistura eclética de estilos, pela adesão às novas tecnologias e aos signos da cultura de massa, e, finalmente, pelo abandono de uma abordagem estética focada no universal e eterno, substituindo-a por uma ênfase na localização espacial e temporal.
} 
identidades e de novos sujeitos no contexto cultural e político (HALL, 2003). O autor explica esse fenômeno como uma disputa que pode gerar "mudanças no equilíbrio de poder nas relações da cultura” (p.339). Precisamente aí, o rap dos Racionais pode ser lido como uma potência artística que engendra "estratégias culturais capazes de deslocar as disposições do poder" (HALL, 2003, p.339) ao apresentar em suas letras um discurso poético de resistência e autoafirmação.

\section{5 "A VOZ DA FAVELA: E FAZ PARTE DELA"}

Como diz Hall (2003), “em certo sentido, a cultura popular tem sempre suas bases em experiências, memórias e tradições do povo. Ela tem ligações com as esperanças e aspirações locais, tragédias e cenários locais que são práticas e experiências cotidianas de pessoas comuns" (p.340). Dentro dessa definição, o rap pode ser visto como uma narrativa poética de caráter cronístico, que retrata a vida cotidiana das populações marginalizadas das grandes cidades do final do século XX e início do XXI, especialmente a vida dos jovens. Os Racionais dizem que eles são a "voz da favela", a "trilha sonora do gueto", pois elaboram em forma de música a "experiência das comunidades populares", da vida local, traduzindo em ritmo e poesia e de forma autêntica as esperanças e aspirações dos jovens negros das periferias urbanas. Assim, como diz Hall (2003), elementos da cultura popular - no caso, o rap - são identificados como tais para que se possa vê-los como expressão de uma "vida subalterna específica, que resiste permanentemente a ser reformulada como baixa e periférica" (p. 341).

Conforme a definição do autor, além de estar enraizada nas experiências populares, a cultura popular também está disponível para expropriação por parte do circuito do poder e das forças econômicas de mercado. Especialmente no mundo contemporâneo, onde tornou-se a forma dominante da cultura global, a cultura popular configura-se como um espaço privilegiado de mercantilização e homogeneização, fazendo com que frequentemente estereótipos e fórmulas submetam o controle de suas narrativas e representações às burocracias culturais estabelecidas. Neste sentido, os Racionais sempre foram arredios em relação ao controle e apropriação externos de sua produção musical. Criaram seu próprio selo (Cosa Nostra) e produtora (Boogie Naipe) para serem sempre criadores independentes e evitarem à sujeição de sua arte a outros atores. No que se refere à indústria cultural, os Racionais, como grupo, nunca se apresentaram nos grandes canais de TV, apenas na TV Cultura (programas "Ensaio", "Roda Viva" e outros) e na MTV (programas "VMB" e "YO!Raps"). 
Hall (2003) aponta também a existência de um caráter contraditório na cultura popular negra, que impediria sua redução aos binarismos mais frequentes: alto/baixo, cooptação/resistência, autêntico/inautêntico, experiencial/formal, oposição/homogeneização. Afirma que neste tipo de cultura não existem formas puras. Mas em vez de pensar por meio da noção de "pureza", diz o autor, seria mais interessante compreender estas formas culturais a partir da observação de "sincronizações parciais" (HALL, 2003, p.343), confluências de mais de uma tradição cultural, negociações entre posições dominantes e subalternas, uma negociação crítica com diferentes fontes culturais e a produção de significação a partir de material preexistente (os samples usados nos raps, por exemplo), criando, assim, uma cultura híbrida para a qual análises que trabalhem com a dualidade autêntico/inautêntico sejam inadequadas e não compreendam o caráter adaptativo das formas culturais nos espaços mistos e contraditórios da cultura popular. Assim, os repertórios atuais da cultura popular negra foram determinados tanto pela herança africana quanto pelas condições diaspóricas.

Para Hall, na arena cultural sempre há espaços a se conquistar e nunca a cultura popular será integralmente incorporada pelos interesses dominantes. E mesmo quando as formas culturais foram cooptadas ou deformadas é possível encontrar ali elementos de resistência e autenticidade que afirmam à tradição de lutas do povo negro na diáspora, a estética negra, que inclui a musicalidade (a "estrutura profunda da vida cultural negra"), a oralidade, a "rica, profunda e variada atenção à fala", as inflexões vernáculas e locais, assim como a produção de contranarrativas por uma comunidade que mantém suas tradições e lutas (HALL, 2003, p.342).

Sob esta ótica, é possível localizar nos Racionais os elementos que Hall descreve como características autênticas da cultura negra. Essas características são: a comunidade negra que manteve tradições e lutas; uma estética ou série de repertórios culturais negros; a produção de contranarrativas negras. A presença da remissão às lutas na diáspora e produção destas contranarrativas é uma das características essenciais do trabalho musical dos Racionais e será apresentada em detalhes na análise da música "Negro Drama" mais à frente. Já a importância da oralidade e a atenção à fala, por exemplo, são evidentes pela presença marcante da figura do MC, que desenvolve sua forma própria de rimar acentuando sua fala no tempo da batida. Essa tradição vem de uma linhagem de formatos de fala/poesia/música, como já foi mencionado, mas que contemporaneamente é oriunda da gíria de rua afroamericana conhecida como "jive talkin", em que o estilo de falar é o ponto de partida para o estilo de "cantar", a partir de uma estética oral sinuosa, rimada, musicalmente dinâmica. Como no rap geralmente não há melodia, o rapper não é exatamente um cantor. Antes, ele é 
um artista da rua que se apropria do "dialeto" falado nas periferias e o utiliza como matéria prima para sua ourivesaria poética e musical. Como MC, Brown, por exemplo, faz um uso bem peculiar do português. Fã de Chico Buarque e Guilherme Arantes, o rapper tem uma verve poética trabalhada, faz metáforas inventivas e cria imagens poderosas e de intensa capacidade de comunicação a partir da reelaboração ritmada da fala do cotidiano. Além disso, nos shows, costuma fazer discursos (que os Racionais chamam de "orelhada") entre uma música e outra.

No que se refere à sensibilidade para a música negra, os Racionais são um caso especial dentro no cenário do rap nacional dos anos 80 e 90, por terem uma relação estreita com esta linguagem artística - talvez mais do que a maioria dos outros nomes do Hip Hop brasileiro. É possível, inclusive, que esta seja uma das razões que explicam o enorme sucesso de seu trabalho. Seu repertório rítmico é rico, tendo em vista a presença frequente do samba, do funk americano e da Soul Music americana nas suas bases. Brown conheceu a música nos terreiros de candomblé ainda na infância, tocou repique de mão num grupo de samba na adolescência e começou a se apresentar como rapper em bailes black. Apaixonado pela música negra brasileira e estadunidense, Brown chega a se ressentir do fato das pessoas sempre o interpelarem para falar de política, e raramente de música.

Ao lado da musicalidade do MC, há a musicalidade do DJ. No caso, KL Jay é grande apreciador de jazz e rock, colecionador de discos, tem trajetória sólida discotecando na noite de São Paulo - para além do trabalho com os Racionais - e costuma dizer que falta suingue aos DJs. Além dele, Brown e Rock fazem as batidas para os raps do grupo. Suas referências para a composição são inúmeras e passeiam com classe por uma boa parte da música negra pop contemporânea: ouve-se samples de Tim Maia, Curtis Mayfield, Cassiano, Al Green, Jorge Ben (em homenagem a quem Brown batizou seus dois filhos, Jorge e Domênica), Almir Guineto, Marvin Gaye, Isaac Hayes, The Meters, Hyldon, Michael Jackson, James Brown (cujo nome serviu de inspiração para o apelido do líder dos Racionais), Leon Hare e outros.

\section{O COMBATE AO RACISMO NA MÚSICA DOS RACIONAIS MC'S}

Ao analisarmos mais de perto as composições dos Racionais ao longo destes 25 anos e a temática racial, é possível pensar em três momentos-chave, algo como três fases, tendo como pontos de referência os anos de lançamento dos álbuns de estúdio. A primeira fase refere-se aos dois primeiros trabalhos: o disco de estreia "Holocausto Urbano", de 1990, e o EP, "Escolha seu caminho", de 1992, de onde analisaremos as músicas "Racistas Otários", do primeiro, e "Negro Limitado", do segundo. A segunda fase contempla os discos "Raio X do 
Brasil", de 1993, "Sobrevivendo no Inferno", de 1997, e "Nada como um dia após o outro", de 2002. Como paradigma desta etapa maior, observaremos a já clássica "Negro Drama", do álbum de 2002. Já da terceira fase, que compreende o trabalho "Cores\&Valores", de 2014, analisaremos "Eu compro".

Em geral, como artistas, os Racionais estiveram sempre envolvidos com o debate racial. Frequentemente referindo-se aos negros como "não indenizados" pelo holocausto da escravidão, eles se identificam como "pretos" a todo tempo, como na célebre alcunha "os quatro pretos mais perigosos do Brasil", através da qual frequentemente se definem. Historicamente próximo do movimento negro, Brown é declaradamente a favor das cotas e participou das duas primeiras Conferências Nacionais para a Promoção da Igualdade Racial, em 2005 e 2009, aonde foi para debater, ouvir e cantar, como declarou em entrevista a AfroPress à época. Informalmente próximo ao PT nas eleições que Lula disputou, sem ter se aproximado efetivamente dos governos petistas apesar de receber convites, o líder do grupo constantemente relaciona a chegada ao poder de Lula e Dilma no Brasil à conquista da presidência dos EUA por Barack Obama, que se elegeu com largo apoio da comunidade negra estadunidense e especialmente da comunidade do Hip Hop.

Como reflexo dessa postura, todo o trabalho dos Racionais é de alguma maneira permeado por reflexões sobre a vida do jovem negro brasileiro. Entretanto, a seleção utilizada nesta pesquisa traz apenas as canções em que o tema racial é o foco principal do discurso verbal (o que fez com que o álbum mais famoso do grupo, o riquíssimo "Sobrevivendo no inferno", ficasse de fora da análise), como se elas sintetizassem em si o pensamento que se encontra disperso pela obra como um todo, e que é também explicitado nas entrevistas que o grupo concede. Trata-se, portanto, de escutar com acuidade tais músicas como paradigmáticas, correlacionando-as com o material discursivo não musical do grupo e com os trabalhos de outros pesquisadores.

\subsection{De 1990 a 1993: Chamada à consciência ou escolha seu caminho}

A primeira etapa do trabalho dos Racionais, o início da carreira, está relacionada a uma descoberta intelectual e conscientização por parte dos membros do grupo, e introduziu nos seus raps uma visão politizada da realidade, compreendida largamente em termos maniqueístas. Nasceu ali uma música engajada, que com um tom professoral e moralizante abordava questões macropolíticas, como o racismo. O traço essencial deste discurso é a chamada dos negros brasileiros à consciência através da convocação dos "manos" a se informarem e se oporem às opressões sociais e raciais, especialmente à violência policial. 
Precursor deste tipo de rap no país, os Racionais estabeleceriam ali o modelo de rap político que se consolidaria nos anos 90: sobre um beat repetido insistentemente, recai um texto rimado de poesia política direta, descritiva e radical.

Curiosamente, neste momento inicial, a linguagem utilizada nos raps é bastante formal. Numa tentativa de identificar elementos poéticos para uma crítica estética do trabalho dos Racionais, Garcia (2004) nota que o recurso de "cantar situações violentas com "palavras de rua mesmo" (Santos, 1997 apud Garcia, p.177) foi conquistado ao longo da trajetória do grupo, "contra o preconceito linguístico e a favor da comunicação com a periferia". Citando (Santos, 1997), o mesmo Garcia lembra que os próprios Brown e Blue já haviam declarado que no começo da carreira o Racionais MC's queria "ser intelectual, falar umas palavras difíceis com 'medo de falar gíria, medo de ser mal interpretado, medo da música ser vulgar'” (Kalili, 1998b, p. 17 apud Garcia).

Este talvez seja o principal atributo formal que recobre a primeira fase do discurso político do grupo como um todo, e especificamente a temática racial. A postura didática em relação aos significados propostos lembra, segundo Garcia (2004):

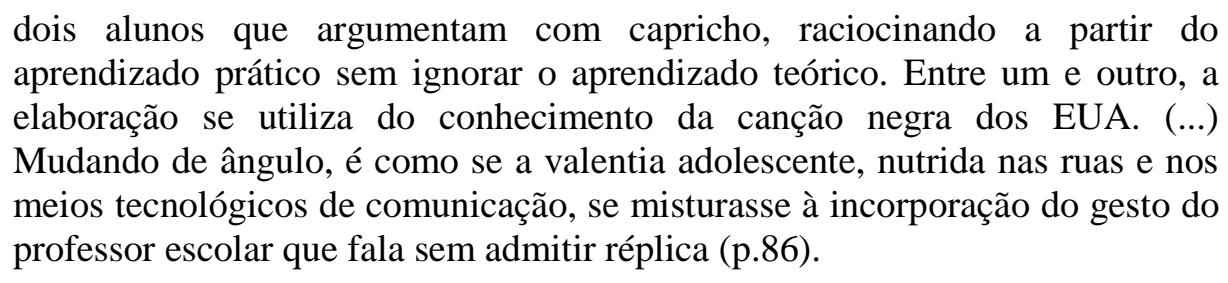

Este era o momento em que o grupo começava a desenvolver uma crescente consciência política, a partir de uma aproximação com o movimento negro. Deste encontro nascem trabalhos como "Racistas otários" $5 "$ (1990) e "Negro limitado" (1992), que refletem o impacto gerado pelo acesso à história de Malcolm X - ícone poderoso da cultura Hip Hop - e dos Panteras Negras. Ao falar sobre este contato, Brown relata a sensação de perceber que sempre tivera no coração aquele tipo de postura combativa em relação a questão racial, mas que até então não conhecera ninguém que fazia aquilo na prática como aqueles nomes.

Sobre o sample de "Ufo" do grupo ESG e de "Thriller", de Michael Jackson, o discurso dos Racionais em "Racistas otários" crítica a realidade vivida pela "gente pobre e carente" que sofre com a indiferença da autoridade, da justiça, que pela sua negligencia deixa que a "periferia se torne um inferno". À época, os Racionais eram jovens negros de 20 anos -

\footnotetext{
${ }^{5}$ A letra completa da música encontra-se disponível no link: http://letras.mus.br/racionais-mcs/796245/

${ }^{6}$ A letra completa da música encontra-se disponível no link: http://letras.mus.br/racionais-mcs/88493/
} 
Brown e KL Jay trabalhavam como office boys - conscientizando-se da dinâmica de forças políticas e econômicas que rege a realidade social brasileira. Tomados por esse processo de conscientização, eles convocam os outros jovens para a luta antiracista, e realizam tal chamado com um rap de tom militante e didático. Criticam a desinformação da periferia e clamam por igualdade, acusando a lei de ser implacável com os oprimidos. Segundo o rap dos Racionais de então, é a lei injusta que torna bandidos os que eram "pessoas de bem".

A crítica à violência policial ${ }^{7}$ já está presente, na denúncia do abuso que mata a "gente negra e carente", que não se verá retratada dignamente nos jornais pois "não é muito influente". O "sistema está falido" e há muito tempo os negros são empurrados para a “incerteza e o crime” pois vivem em condições precárias, cantam os Racionais. A "sociologia dirá que o problema é financeiro", mas Brown lembra que "o negro e branco pobre se parecem, mas não são iguais". Neste momento, o grupo já se mostra atento à crítica que é frequentemente mobilizada no Brasil contra a política de cotas, que afirma que elas deveriam obedecer ao critério econômico e não ao racial.

No final dos anos 80, os Racionais criticavam o estereótipo do negro como criminoso, estigmatizado por conta do cabelo, da cor e da feição que fazem dele "um marginal padrão". Lembram-se dos seus "ancestrais, que lutaram e morreram por igualdade" e queixam-se dos outros negros que sofrem os efeitos perversos do racismo do cotidiano, mas continuam de "braços cruzados", sem reagir. Num revide artístico antirracista em forma de rap, acusam a lei antirracismo de não funcionar na prática (provavelmente referem-se à lei Lei 1390/51 de Afonso Arinos, de 1951, que depois seria substituída pela Lei 7716/89 proposta pelo advogado Carlos Alberto Caó Oliveira dos Santos, de 1989).

Antecipando a disposição para não ser cordial que caracterizaria seu trabalho musical subsequente, os Racionais nos seus primeiros momentos musicais já debocham da caricatura que retrata o Brasil como um país tropical onde as "as raças se misturam naturalmente, e não há preconceito racial". A grande risada após o anúncio do mito conservador mostra o início de um processo em que os Racionais reelaboram dentro da música a história do negro no Brasil, contradizendo no seu rap a argumentação do senso comum branco, que se apoia em Gilberto Freyre (2006) para falar sobre a miscigenação no país. Formado por jovens de apenas 20 anos, o grupo engaja-se num dos maiores desafios do movimento negro brasileiro: afirmar a

\footnotetext{
${ }^{7}$ Crítico da brutalidade policial nas favelas, anos depois, em entrevista à AfroPress na Conferência Nacional de Promoção da Igualdade Racial, Brown disse que historicamente a polícia foi criada para capturar escravo "fujão", e que essa seria a razão social da polícia até hoje.
} 
existência do racismo no país para justificar a luta antirracista e a futura adoção de políticas públicas a respeito do tema.

Já sobre o sample de "Walk on By" de Isaac Hayes, na música "Negro limitado", Edi Rock tenta chamar os outros "manos" para a consciência e discutir a questão do negro. No entanto, seus interlocutores estão apenas interessados em "curtição e dinheiro" e estereotipam Rock, o militante, como "revoltado". Neste rap, os jovens desinteressados da luta política contra o racismo são vistos como "limitados", "estúpidos". A mensagem é clara: os negros não sabem sua origem, mas deveriam saber, e usar sua cultura para se opor à opressão racista. Como fazer isso? Os Racionais dão a receita: cultura, educação, livros e escola. A vida do “crime e da vagabundagem" é o caminho mais fácil, lembra o grupo. Mas ele leva à morte pela polícia, que se regozija em "matar mais um negro", rima Rock. Tal qual o norte americano Public Enemy - principal representante do rap político de Nova York que se intitulava "a CNN dos negros" - os Racionais também trabalhavam com a ideia de prover informação, uma noção cara ao hip hop mais engajado.

\subsection{De 1993 a 2002: Autoestima para sobreviver no inferno}

O estilo inicial do primeiro momento da carreira se transforma e configura uma segunda fase, que compreende o período de 1993 a 2014. Esta nova etapa do processo artístico pode ser localizada em seu nascedouro no disco de 1993, mesmo que, a princípio, em termos gerais, faça mais sentido demarcar o momento de inflexão no disco de 1997, "Sobrevivendo no Inferno", como fazem Oliveira; Segreto e Cabral (2013). De fato, é neste trabalho que se apresenta de maneira mais sólida e integral uma renovação estética e discursiva que viria a consagrar os Racionais e tornar-se sua assinatura.

Entretanto, em entrevista à TV Cult, o próprio Brown aponta "Fim de semana no parque", do álbum "Raio X do Brasil" (1993), como o início de uma "outra fase". Logo, seria imprudente ignorar a delimitação do próprio compositor e não localizar ali o início desta nova etapa que, é verdade, só viria a se consolidar de forma mais completa no disco seguinte. No limite, o que está em jogo aí é a ideia central de que a carreira do grupo esteve sempre em metamorfose, caminhando em paralelo com as questões éticas, criativas e políticas que inquietavam as sensibilidades de seus membros.

Uma das principais transformações observadas é a mudança no lugar de fala do grupo. $\mathrm{Na}$ fase anterior, os Racionais eram conhecidos predominantemente apenas na periferia de São Paulo. Já em 2002 (ano do lançamento de "Negro Drama”), o grupo era conhecido em todo o país como o maior grupo de rap do Brasil e já havia chegado à MTV. Àquela altura, os 
Racionais saiam da condição de jovens de 20 anos então no processo de desenvolver uma visão política da realidade, para tornarem-se artistas conhecidos e em progressivo processo de expansão de suas potencialidades musicais e poéticas. Logo, aos poucos, as letras vão abandonado sua faceta puramente descritiva e sua verve pretensamente intelectualizada para revestir-se de maior riqueza poética, repleta de metáforas, imagens e analogias que incorporam o dialeto das ruas.

No que se refere à questão política, a poesia dos Racionais intensifica sua disposição para não ser cordial e desnudar sem medo as contradições da sociedade brasileira. Nesse sentido, é interessante a caracterização feita por Garcia (2004), que descreve o rap dos Racionais como uma espécie de revide, ressaltando seu talento para cantar a violência ao ser contundente, sem cair no melodrama ou no sadismo. Como o próprio Brown explica, o que os Racionais fazem artisticamente é usar a violência contra a violência, buscando a paz de forma violenta. (GARCIA, 2004)

Nesta fase, a relação com o interlocutor também se altera. No lugar de um discurso do alto para baixo, moralizante, em que o MC pretende doutrinar o público, revelando a ele a "verdade", Rock e Brown passam agora a falar de suas experiências particulares. A partir de um artesanato poético em franco desenvolvimento, os rappers vão costurando à crônica da realidade social em que vivem uma abordagem mais subjetiva e pessoal, fundindo questões sociais com questões pessoais, conforme Garcia (2004) também nota. Neste momento, os Racionais percebem que podem falar de suas vidas, seus dilemas, suas questões, seus desafios, utilizando seus versos para articular essas experiências (micropolíticas) a processos (políticos) maiores.

É da mistura entre um lugar de fala mais horizontalizado, em que o MC faz uma ponte entre o particular e o geral, e a utilização mais natural de recursos poéticos que nasce a força do discurso dos Racionais. A compreensão dessa alquimia nos ajuda a entender o sucesso do grupo e a adesão de seu público, que canta letras de quase 10 minutos em uníssono nos seus shows lotados

Em "Negro Drama" (2002), sobre um sample de "Ain't No Superman", de Jake the Flake, se colocam os versos de Brown e Rock, que dividem o microfone cada um em seu momento e apresentam com excelência esse "projeto" ético e estético. A música abandona a aridez da reivindicação militante e da crítica sociológica e parte para a criação de uma nova paisagem: serão eles agora, os Racionais, os responsáveis por elaborar uma nova

\footnotetext{
${ }^{8}$ A letra completa da música encontra-se disponível no link: http://letras.mus.br/racionais-mcs/63398/
} 
representação da vida do jovem das favelas, serão os negros do rap brasileiro que (re)contarão sua história na diáspora. Neste momento, os Racionais fazem avançar um enfrentamento que já havia começado nos trabalhos anteriores e sangram ainda mais o mito da democracia racial (PINHO e ROCHA, 2011). Nesta fase, uma nova história ganhará contorno e os Racionais não vão apenas apontar as mentiras do discurso hegemônico: antes, eles vão propor um novo discurso, uma nova ética, uma nova forma de estar no mundo.

Repondo o negro na condição de protagonista de sua própria história, os Racionais desmontam a argumentação Freyreana de que a miscigenação no Brasil equilibrou os antagonismos de classe da nossa formação cultural. Os Racionais arrancam o véu que encobre a hierarquia social que submete os negros diariamente (ver o negro "pobre, preso ou morto já é cultural") e revelam, com agressividade e sem receio de falar de contra-ataque, a falácia da mitologia do povo pacífico onde estão todos misturados e em harmonia. À sua maneira, os Racionais reinterpretam a história do negro no Brasil, resignificando como "conflituosa e sanguinária" a relação entre pretos e brancos, senhores e escravos, capitão do mato e negro fugido, patriarcas e escravas (PINHO e ROCHA, 2011). A esta altura, o grupo se vale de um traço essencial da cultura popular negra, como enunciado por Hall (2003): o uso metafórico do vocabulário musical para trazer à tona, mesmo através de uma modalidade cultural mista como o rap, uma outra tradição de representação que opera como uma contranarrativa. Quando Brown diz "Um bastardo, mais um filho pardo, sem pai/ ei, senhor de engenho eu sei bem quem você é" é essa contra interpretação que está em jogo em sua poesia.

Ao analisar a dimensão política do Hip Hop americano, Rose (1994) sugere um embate semelhante. Segundo ela, os grupos dominantes valem-se de estratégias para simular unanimidade a respeito do poder estabelecido. Este, diz ela, oculta discursos que questionam suas vitórias simbólicas. Quando rima com sua voz grave o drama que ele mesmo encarna, Brown destrói essa barreira e cria, através da música, um discurso de oposição que conta estórias capazes de inverter estigmas e chamar a atenção para uma alternativa que valida a percepção dos menos poderosos e que se origina no grupo ao qual ele pertence

Em outras palavras, os Racionais usam o rap para nomear o que os jovens negros da periferia de São Paulo sentem: a miscigenação não corrigiu as distâncias sociais. Antes, ela encobre a explicitação de uma estrutura segregada e violenta ("a farda que pratica o mal”) que mantém os negros em posição subalterna. Assim, num ginásio da Zona Leste de São Paulo - o maior centro capitalista do Brasil - eles demolem o mito da unidade nacional. A poesia crítica ecoa poderosa nos ouvidos de um público que sabe muito bem do que eles estão falando, pois sempre sentiu pesar sobre suas costas a mentira da convivência pacífica. Como diz Garcia 
(2004), o rap mobiliza de tal forma o público que não é difícil sentir uma ação coletiva em potencial ali, pronta para subverter a herança de desigualdade econômica e de segregação social.

Neste momento, os Racionais criam, como afirma Oliveira; Segreto e Cabral (2013), um discurso coletivizado, de estabelecimento de vínculos e convergências, que de alguma forma produz uma ideia de representatividade a partir da identidade entre o jovem da periferia e a "retórica profética" do grupo. Como afirma Garcia, "condensada em uma forma lapidar, a experiência se torna conceito, sabedoria popular que sugere regras de conduta" (GARCIA, 2007, p. 214). A partir desta afirmação, acreditamos ser possível argumentar que esta condensação cria o terreno para uma proposição ética por parte do rap do grupo, que afirma a autoestima daquele jovem brasileiro e versa sobre os desafios de viver na favela com inteligência.

Distante do sermão que caracteriza a poesia dos seus primeiros trabalhos, os Racionais sugerem a criação de uma vida ativa - longe das drogas e do crime, que levam à morte. Mas também distante da submissão ocasionada por uma inserção subalterna na ordem econômica. Valendo-se de mecanismos de empatia e identificação, os Racionas elaboram um ethos que sugere uma forma alternativa de viver. Assim, o grupo reconhece e afirma a ancestralidade negra e sua autoestima, valoriza o espírito coletivo na favela ("coletividade na quebrada", diz Brown) e sua comunidade étnica, resiste aos valores associados ao consumo da sociedade capitalista e recusa uma postura conciliatória com a classe média e as elites acusando-as frontalmente pelas injustiças sociais (OLIVEIRA; SEGRETO e CABRAL, 2013).

Além disso, a inclinação moralista da primeira fase sai de cena e abre terreno para a emergência de conflitos de pensamento no discurso. Os Racionais, agora, já não se mostram tão resolutos a respeito do que dizem, já não carregam na sua poética as verdades claras que entoavam no início da carreira. Especialmente Brown questiona suas próprias convicções, como se ele, como individuo, fosse consciente de que suas contradições particulares estão relacionadas às do Brasil. Intelectual das ruas em constante processo de reflexão, Brown articula contradições de naturezas distintas para refletir sobre um desafio: encontrar a “fórmula mágica da paz” para viver com altivez e dignidade num contexto violento e racista.

\subsection{4: Eu quero, eu compro no mundo do pós-lula}

Há um longo intervalo de tempo entre o disco "Nada como um dia após o outro dia", de 2002, e o trabalho seguinte com música inéditas, "Cores e Valores", de 2014. Os 12 anos de distância entre uma obra e outra fazem um paralelo quase exato com a chegada e 
permanência do PT no comando do Executivo Federal, o que ocasionou algumas transformações na realidade das periferias brasileiras, assim como na vida econômica de parcelas significativas das classes populares como um todo. Um conjunto de políticas públicas implementadas produziu mudanças consideráveis no que se refere ao acesso à renda, educação e consumo e à efetivação de medidas relacionadas às demandas do movimento negro.

Além de levar em conta as alterações do cenário socioeconômico do país, tentar entender uma possível nova fase do discurso racial do grupo precisa considerar o fato de que os integrantes dos Racionais são hoje artistas estabelecidos que desenvolveram carreiras solo e que contam entre 44 e 45 anos de idade. Ou seja, o Brasil mudou e os compositores dos Racionais também mudaram. Mas, e o discurso do grupo a respeito de ser negro no Brasil, também mudou?

É fato que os Racionais continuam abordando as temáticas que os consagraram: a difícil condição do negro na ainda fortemente desigual sociedade brasileira, a violência policial e as contradições da vida na periferia. Entretanto, outros elementos aparecem em cena neste momento. Há em todo o trabalho um tom mais maduro. As canções são mais diretas e emerge dali um olhar mais ponderado na hora dos posicionamentos políticos. Os temas mais espinhosos são atacados de forma lateral, salvo poucas exceções. No que nos interessa, talvez a principal diferença em relação às fases anteriores seja a abordagem da temática racial, atrelando-a diretamente à questão do consumo.

Com evidente feição gangsta, a música "Eu compro"" revela essa aproximação. Nela, Ice Blue lista marcas de relógios, roupas, carros e motos e questiona o racismo implícito numa certa crítica que é feita ao consumo das pessoas oriundas das favelas, especialmente dos negros. Ao processo de incremento na renda das classes populares no Brasil, frequentemente é associada a ideia de um consumismo desenfreado e inadimplente, ou uma incapacidade de perceber quais "deveriam ser" as reais necessidades de consumo dessa classe (que, sociologicamente, não é uma nova classe média, mas uma classe trabalhadora ascendente) agora alçada à posição de consumidora devido à expansão do emprego formal e aumento do salário mínimo acima da inflação.

A discussão política acerca do consumo/ostentação dentro do mundo rap é extremamente controversa. Os Racionais sempre tiveram um discurso difuso em relação a adesão aos signos do consumo. Versos de "Capítulo 4, Versículo 3" como "seu comercial de

\footnotetext{
${ }^{9}$ A letra completa da música encontra-se disponível no link: http://letras.mus.br/racionais-mcs/eu-compro/
} 
TV não me engana, eu não preciso de status nem fama" sugerem uma postura crítica ao capitalismo brasileiro e ao "sistema". A música "Eu compro", no entanto, sugere uma flexibilização e complexificação desta postura, em um novo momento dentro da reflexão do grupo, que já vinha relativizando suas posições mais radicais ${ }^{10}$.

Além de levar em conta o mencionado processo de ascensão econômica, é preciso considerar também transformações relacionadas à implementação de políticas específicas que começaram a reconfigurar o lugar do negro na sociedade brasileira, tornando-o relativamente diferente da posição ocupada nos anos 90.

Mesmo não tendo implementado reformas estruturais e profundas no acesso à cidadania no país, os governos petistas foram responsáveis pelo avanço de políticas públicas em relação à questão racial. Ao discutir as ações de inclusão racial dos governos de Lula e Dilma, Júnior; Daflon e Campos (2012) afirmam que o Lulismo não assumiu a ação afirmativa como uma bandeira de governo, mas permitiu que o Estado e a sociedade civil estabelecessem uma conversação que redundou no sucesso dessas iniciativas. Em 2003, por exemplo, foi criada a SEPPIR (Secretaria de Políticas de Promoção da Igualdade Racial) e foi sancionada a lei que determina o ensino de história da África nas escolas. Em 2004, foi lançado o ProUni e o Programa Brasil Quilombola. Já em 2007, o governo federal implementou o REUNI, tendo as ações afirmativas como condicionalidade. Em 2010, aprovou o Estatuto da Igualdade Racial e em 2014 sancionou a lei que que estabelece $20 \%$ de cotas para negros em concursos federais.

\section{CONSIDERAÇÕES FINAIS}

A pesquisa analisou o rap como uma estética de forte viés político no mundo contemporâneo, dentro da diáspora, caracterizada como um espaço de debate e resistência cultural dos negros. No caso brasileiro, os Racionais MC's desempenharam o papel de destacado elaborador de um discurso de combate ao racismo com um forte viés ético, que versa sobre a vida do jovem negro da periferia de São Paulo. Este discurso passou por

\footnotetext{
${ }^{10}$ É verdade que os Racionais continuam sem aparecer nos grandes canais da mídia tradicional do Brasil e já recusaram contratos com grandes gravadoras. Contudo, já há algum tempo, eles vêm relaxando suas posições mais radicais. Edi Rock foi divulgar seu disco solo no programa de Luciano Huck da TV Globo. Ice Blue participou do clipe de Tulio Deck - claramente um rap de estilo ostentação. Brown também já havia aceitado participar de publicidade da multinacional Nike ao lado de Jorge Ben. Em 2013, numa apresentação na boate de elite, Royal, em São Paulo, Brown disse à revista Rolling Stone que estava ali para "fazer negócio", sem "pagar pau" para ninguém. Em matéria na mesma revista, ele também relata que o grupo faz o que chama de shows "Robin Hood": quem tem mais dinheiro paga mais para ver os Racionais, quem tem menos, paga menos ou até mesmo nada
} 
transformações ao longo dos 25 anos de carreira que foram representadas por três fases distintas.

A primeira relaciona-se a uma descoberta intelectual e política, que produziu uma visão mais militante a respeito da realidade, e fez nascer os primeiros raps do grupo - mais engajado em sentido estrito e de tom professoral. Na segunda fase, o trabalho musical dos Racionais mudou seu lugar de fala e passou a falar da periferia como um todo, com uma intenção menos didática e moralizante. A faceta cronística do rap entrou em jogo aqui para conjugar os problemas individuais do rapper narrador aos problemas sociais que ele enfrenta no dia a dia. A música do grupo passa a levar mais em conta os questionamentos subjetivos do MC, agora menos convicto e mais questionador, menos descritivo e mais poético. Jogando com uma lógica mais horizontal de identificação com o coletivo da juventude negra das favelas, os Racionais construíram uma carreira de sucesso comercial e reconhecimento artístico nesta fase. Com esta alquimia, o grupo deu origem a um projeto estético e ético para vida na periferia cativando multidões de jovens e transformando a cena do rap nacional e dos negros brasileiros, que a partir de então teriam uma outra referência discursiva para pensar sua própria realidade e agir sobre ela.

Já a terceira fase do discurso racial dos Racionais não abandona o tema da violência policial ou a promoção de uma ética de vida, mas repõe sua ênfase na questão do consumo. Um grupo de rappers com mais de 40 anos de idade já não diz a mesma coisa que dizia aos 30, especialmente quando o contexto socioeconômico em que essa música é produzida alterou-se significativamente. Nessa conjuntura, a ascensão social da classe trabalhadora brasileira e sua maior inserção no mercado de consumo entra no foco dos Racionais que - não sem levar em conta as controvérsias do assunto - questionam as críticas recebidas pelas classes populares por conta desta inserção.

Dessa maneira, a música dos Racionais, observada em perspectiva, apresenta um movimento contínuo de mudanças musicais, discursivas e políticas. Hoje artistas de sucesso, os Racionais viram na última década e meio políticas públicas compensatórias para os mais pobres e para os negros sendo encampadas pelo Estado brasileiro. Na esteira de melhorias pontuais e transformações históricas mais amplas, o próprio Brown redefine o significado de "revolução":

É mostrar envolvimento, você pôr sua inteligência dentro dela, sua mão de obra, o conhecimento que você aprendeu naquela causa. Como é que você consegue mostrar isso? Quando a sua empresa vai bem, quando você paga as pessoas direito, quando você dá emprego para mais pessoas. Aí é trabalho! Não é movimento, onde um faz e fica um monte de gente sem condições de fazer nada. Tem que dar condições das pessoas fazerem para ganharem seu 
dinheiro. Esse é o momento que a gente está vivendo hoje. Essa é a maior evolução. Já não é revolução do discurso, das coisas abstratas, morou? É do trabalho. Se fosse no campo, seria enxada e terra. É na cidade. É trabalho. É envolvimento. É vida, sabe? E é ideologia também. (...) Você tem que conseguir fazer sua parte, saber que muito mais gente vai ser beneficiada com aquela atitude que você tomou. Não uma atitude que vai fazer bem para você, encher seu ego. Então, o "revolucionário" tem que passar a ser útil. Parar de ser mentor dos comuns. Não! Vai crescer junto. (BRAZ, 2014)

Diante das mudanças de contexto e dos sentidos dos discursos, Mano Brown continua na mesma entrevista, ele se recusa a cantar as "músicas revolucionárias" como se isso fizesse algum efeito, elogia o programa Esquenta, de Regina Casé na TV Globo, e diz que se rebelião é cantar o amor, cantará.

O Brasil continua sendo uma sociedade estruturalmente desigual, onde moradia, educação de qualidade, saúde, esgoto tratado, segurança e a possibilidade da execução livre dos planos de vida individuais ainda são privilégios de minorias e não direitos universalizados. E apesar do novo tempo e de sua crescente incorporação pelo mercado, o rap, como cultura de rua, ainda parece ser capaz de produzir uma ética de autoestima para a existência dura de largas parcelas da juventude negra e das periferias do Brasil. Dentro destas tensões, emerge um Racionais maduro, que não aderiu ao "sistema" e não renega seu passado combativo, mas que já não é mais o Racionais dos anos 90 e 2000.

\section{REFERÊNCIAS}

AFROPRESS. Entrevista com Mano Brown. Disponível em:

<https://www.youtube.com/watch?v=59bSX0ay9wY>. Acesso em: 21 fev. 2015.

BERTELLI, Giordano Barbin. Errâncias racionais: a periferia, o RAP e a política.

Sociologias, Porto Alegre, ano 14, n. 31, 2012, p. 214-237.

BORGES, Raphael; ALMEIDA, Ivy. Estação Periferia: Racionais MC's. Disponível em: <https://www.youtube.com/watch?v=0Hf9IUsdMbo>. Acesso em: 10 mar 2015.

BRAZ, Endrigo Chiri. "Eu questiono porque não basta ser": Entrevista a Mano Brown.

CULT, Ano 7, vol. 192, julho 2014. Disponível em:

http://revistacult.uol.com.br/home/2014/07/eu-questiono-porque-nao-basta-ser/. Acesso em 19 ago. 2014.

CALDEIRA, Teresa. Enclaves fortificados: a nova segregação urbana. Novos Estudos

CEBRAP 47, 1997, p. 155-76. 
CARAMANTE, André. Os quatro pretos mais perigosos do Brasil. Entrevista com os Racionais MC's. Rolling Stone, 86, 2013, p. 72-81.

DUNCOMBE, Stephen. Introduction. In: Cultural Resistance Reader. London: Verso, 2002, p. 1-15.

FREYRE, Gilberto. Casa grande \& senzala. São Paulo, Global Editora, 2006.

GARCIA, Walter. Elementos para a crítica da estética do Racionais MC'S (1990-2006). Ideias, 7, 2013, p.81-110. 'Diário de um detento': uma interpretação. In: NESTROVSKI, A. (Org.).

Lendo música. São Paulo: Publifolha, 2007. p. 179-216.

GUTIERREZ, Gabriel. A festa e a luta: São Paulo e o rap político dos Racionais MC's. Comunicação oral apresentada no $10^{\circ}$ Encontro Internacional de Música e Mídia. Musimid 2014.

HALL, Stuart. Que "negro" é este na cultura negra? In: Da diáspora:

identidade e mediações culturais. Brasília, UFBG, 2003, p. 335-352.

JÚNIOR, João Feres; DAFLON, Verônica Toste; CAMPOS, Luiz Augusto Campos. Ação afirmativa, raça e racismo: uma análise das ações de inclusão racial nos mandatos de Lula e Dilma. Revista de Ciências Humanas, Viçosa, v. 12, n. 2, 2012, p. 399-414.

KELLNER, Douglas. A cultura da mídia. São Paulo, EDUSC, 2001.

MACEDO, Iolanda. A linguagem musical do Rap: expressão local de um fenômeno mundial. Tempos Históricos, v.15, 2011, p. 261-288.

OLIVEIRA, Leandro Silva; SEGRETO, Marcelo; CABRAL, Nara Lya Simões Caetano. Vozes periféricas: expansão, imersão e diálogo na obra dos Racionais MC's. Revista do Instituto de Estudos Brasileiros, 56, 2013, p. 101-126.

PINHO, Osmundo; ROCHA, Eduardo. Racionais MC's: Cultura Afro-Brasileira Contemporânea como Política Cultural. Afro-Hispanic Review, 2011, p.101-114.

RACIONAIS MC'S. Holocausto Urbano. RDS Fonográfica/Zimbabwe Records, RDL 4006, s.d. 1 CD [p1990] 
Escolha o seu caminho. São Paulo: Zimbabwe Records, p1992, v. 1. . Sobrevivendo no inferno. Casa Nostra/Zambia, ZA-050-1,2002. 2 CDs. . Nada como um dia após outro dia, Casa Nostra/Zambia, ZA-050-1,

2002. 2 CDS.

Cores e Valores. São Paulo: Cosa Nostra e Boogie Naipe (gravadoras),

2014. CD.

SILVA, José Carlos Gomes. Rap na cidade de São Paulo: música, etnicidade e experiência urbana. 1998. (Doutorado em Ciências Sociais) - Instituto de Filosofia e Ciências Humanas, Universidade Estadual de Campinas.1998.

ROSE, Tricia. Black noise: Rap Music and Black Culture in Contemporary America. Connecticut: Wesleyan University Press, 1994.

SHUSTERMAN, Richard. Vivendo a arte. Editora 34, 1998.

TAKEUTI, Norma Missae. Refazendo a margem pela arte e política. Nómadas, v.32, 2010, p. 13-26.

Original recebido em: 30/04/2015

Aceito para publicação em: 28/07/2015

Gabriel Gutierrez, Mendes Mestre em Ciência Política pelo IUPERJ Professor e Pesquisador do departamento de Comunicação das Faculdades Integradas Hélio Alonso 